\title{
ПОНИМАНИЕ ПРАВОВОГО ГОСУДАРСТВА КАК СОЦИАЛЬНОГО В ОТЕЧЕСТВЕННОЙ ТЕОРИИ ПРАВА
}

В работе изложено авторское видение теории социального государства как модели эффективного правового государства. Эффективное государство рассматривается как социетальная система, в которой активно идет процесс смены отношений и процессов на уровне общества. Приведены позиции отечественных и зарубежных правоведов (Роберта фон Моля и Лоренца фон Штейна, С. С. Алексеева, П. П. Глущенко, О.В.Родионовой, В. Г. Баева, М. А. Рейснера, Б. Н. Чичерина и др.).

Авторами подчеркивается мысль, что общество, государство и граждане заинтересованы в обоснованном воздействии права на социальные процессы. В правовой сфере генеральной перспективой становится формирование новой социальной концепции права. Вместе с тем, в настоящее время не удается обеспечить личное влияние людей на процессы правотворчества и правоприменения и преодолеть такое отрицательное явление, как отчуждение от права. Основным результатом функционирования эффективного государства как модели социального государства авторы предлагают считать отсутствие у граждан нуждаемости в государственной помощи для удовлетворения своих минимальных потребностей (естественных, физиологических, потребности в безопасности)
Цель любой модели государства, как организации политической власти, в частности модели эффективного социального государства - обеспечение единства и целостности общества, осуществляемое посредством государственного механизма управления делами общества, суверенной публичной власти, придающей праву общеобязательное значение, гарантирующей права и свободы гражданам, законность и правопорядок, где эффективность рассматривается через призму социальной эффективности. При ее реализации необходимо учесть готовность органов управления как системы, субъектов ее управления и аппарата государства к ее пониманию, исполнению и реализации адекватно временным, историческим и эволюционным параметрам.

Взаимодействие элементов правового социального государства рассмотрено авторами сквозь призму синергетических процессов флуктуации, отвечающих за адаптацию современной социальной политики правового государства к новым правовым реалиям.

Ключевые слова: социальное государство, правовое государство, социальная функция, российский либерализм, социентальная система, эффективное государство, правовое регулирование, правотворчество, правовое воздействие.

\section{Sh. Galstyan, R. K. Melekayev}

\section{UNDERSTANDING THE RULE OF LAW AS A SOCIAL STATE IN THE DOMESTIC THEORY OF LAW}

The paper presents the author's vision of the theory of the social state as a model of an effective legal state. An effective state is considered as a societal system in which the process of changing relations and processes at the level of society is actively underway. The positions of domestic and foreign lawyers are given (Robert von Mol and Lorentz von Stein, S. S. Alekseev, P. P. Glushchenko, O. V. Rodionova, V. G. Baeva, M. A. Reisner, B. N. Chicherin, etc.)

The authors emphasize the idea that society, the state and citizens are interested in the grounded impact of the right on social processes. In the legal sphere, the general perspective is the formation of a new social concept of law. However, at present, it is not possible to ensure the personal influence of people on the processes of lawmaking and law enforcement and to overcome such a negative phenomenon as alienation from the law. The authors suggest that the main result of the functioning of an effective state as a model of a social state is the lack of citizens' need for state aid to meet their minimum needs (natural, physiological, security needs)
The goal of any state model, as an organization of political power, in particular, an effective social state model, is to ensure the unity and integrity of society, implemented through the state mechanism for managing the affairs of society, sovereign public power, giving the right a universally binding value guaranteeing the rights and freedoms to citizens, law and order, where efficiency is viewed through the prism of social efficiency. When implementing it, it is necessary to take into account the readiness of the governing bodies as a system, the subjects of its management and the state apparatus for its understanding, execution and implementation of adequate time, historical and evolutionary parameters.

The interaction of elements of a legal social state is considered by the authors through the prism of synergistic fluctuation processes responsible for the adaptation of the modern social policy of the legal state to new legal realities.

Key words: social state, legal state, social function. Russian liberalism, social system, effective state, legal regulation, lawmaking, legal influence. 
Разработка теории социального государства чрезвычайно важна, поскольку реализация социальной функции государства способна принести и приносит обществу столь же огромную пользу, сколь разрушительными (и экономически, и психологически, и политически) могут быть ее недооценка и необоснованное в конкретных исторических условиях гипертрофирование [1]

Актуальность категории «социальное государство» вызвана не только теоретическими, но и практическими тенденциями реализации данного явления, а также социально-политическим свойством исследуемой дефиниции. Если «социальное» понимать как “общественное», то в этом контексте «социальным» может быть названо любое государство. Однако нас интересуют государство как институт, а также способы, механизмы управления им и степень достигаемости целей управления.

Для более детального изучения понятия «социальное государство» обратимся к работам послужившим основополагающими концепциями социального государства. Среди них выделяются труды правоведов Роберта фон Моля и Лоренца фон Штейна.

В 1832 г. была опубликована книга Р фон Моля «Наука полиции под началом юридического государства», в которой автор предложил «концепцию нового государства», согласно которой за каждым признавалось равенство прав и социальных возможностей, а вопросы поддержки бедных слоев населения относились к обязанностям государства: «...хотя чувство справедливости и сострадания к несомненной нужде человека не допускает строгого взвешивания юридической обязанности государства, но, что, тем не менее, даже чисто с точки зрения права можно требовать вспомоществования" [6].

Понятие и назначение социального государства по-разному определяли российские ученые. Так, С. С. Алексеев считал, что «государство в социальной сфере во всех больших масштабах выступает не как институт власти, а как общенациональная авторитетная (а не авторитарная) корпорация, однопорядковая в данном отношении по своему статусу с соответствующими инициативно-частными организациями» [3]

По мнению П. П. Глущенко, социальное государство - это такое государство, в котором социальные противоречия преодолеваются эффективно работающими государственными структурами и представленными в них неподкупными компетентными государственными служащими [4]. Как мы видим, здесь автор рассматривает социальное государство через механизм государства, «винтиком» которого и его воплощением является государственный аппарат с корпусом государственных гражданских служащих.

В настоящее время в отечественной и зарубежной науке существует многообразие толкований понятия «социальное государство». Основная проблематика теоретического трактования данного понятия заключается в том, что в большинстве случаев на социальное государство ученые смотрят как на политико-правовое и социальное образование, главной целью которого является перераспределение материальных благ исходя из принципов социальной справедливости и равенства. Но для того чтобы блага равномерно распределялись, и система управления этим процессом была эффективна, необходимо повышать эфффективность производства самих благ, и речь здесь идет не только о производительности труда, результативности и экономической эффективности. По мнению автора, государство становится эффективным в том случае, если у его граждан отсутствует нуждаемость в государственной помощи для удовлетворения минимальных потребностей.

Основными задачами в социальной сфере становятся повышение качества жизни населения и обеспечение достойного уровня жизни каждого гражданина и гарантий для тех, кто по объективным причинам не в состоянии реализовать свой потенциал.

Вышесказанное позволяет понимать под социальным государством такую политическую организацию общества, механизм государства в которой, представленный эффективным государственным аппаратом, создает целостную и эффективную систему жизнедеятельности общества и содействует возникновению институтов гражданского общества, в том числе различным формам самоорганизации граждан и организаций, повышению качества жизни граждан и организаций, их правовому и правомерному взаимодействию и развитию системы независимого местного самоуправления для решения вопросов местного значения.

Рассуждая о соотношении правового и социального государства, профессор О. В. Родионова пишет, что «идея правового государства», где права и свободы любого человека превыше всего (права индивида, принцип индивидуализма), а представители государственной власти подчиняются законам наравне с простыми гражданами, является настолько заманчивой, что люди еще долго будут верить в возможность ее полной реализации, не задумываясь о том, что далеко не каждый человек способен самостоятельно пользоваться свободами, и что некоторые люди ищут поддержки со стороны государственно-организованного общества. Большинство стран мира, провозглашает себя «правовыми», во многом из-за того, что в современном мире права и свободы это составляющие идеологии любого государства, позиционирующего себя как правовое, хотя очевидно, что очень многие страны не являются правовыми, так как не отвечают требованиям данного типа государства [7].

Что касается социального государства, то, по сути, социальное государство является частью деятельности государства, ориентированный на защиту нуждающихся групп населения от различных социальных рисков. И хотя базисными принципами социального государства являются равенство, коллективизм, что, казалось бы, должно приводить к противоречиям между этими 
феноменами: правовым государством и социальным государством, однако никакого противоречия между ними не возникает. Дело в том, что социальным в той или иной мере в контексте той или иной модели социального государства (по Эспин-Андерсену, или по иным классификациям) государство с неизбежностью становиться, когда достигает индустриальной стадии развития общества. То есть любое государство (с любым территориальным устройством, с любой формой правления, с любым политическим режимом) в той или иной степени будет социальным. В том числе и правовое государство. Однако, провозглашая себя правовым государством в Конституции, в реальности государство таковым полностью стать не может, в этом и заключается весь парадокс.

Социальная функция современного российского государства, по мнению О. В. Родионовой, модифицируется таким образом, что патернализм государства заключается не в дотационных долгосрочных выплатах всем нуждающимся без разбора, не в безоглядном патронаже, а, прежде всего, в создании условий для граждан, желающих включиться в активную трудовую жизнь (переквалификация, обучение и т. п.) [7].

Сегодня, Российская Федерация существует в рамках индустриального общества. И поэтому, так или иначе, здесь с неизбежностью будет присутствовать социальная функция. А вот ее методы реализации и качественные характеристики обусловлены самыми различными детерминантами. Поскольку современная Россия существует в рамках мирового сообщества, то неизбежным становиться влияние на социальную функцию Российской Федерации, таких детерминант, как, прежде всего рыночная экономика, исторические и этнонациональные особенности, политический режим, и, конечно, глобальные проблемы, связанные с глобализацией.

Идея «правового государства» является чуждой для российского менталитета, так как это западная идея. Как отмечает, О. В. Родионова, государственное устройство конкретного государства должно опираться исключительно на результаты всего предшествующего развития именного данного государства. Ш. Монтескье говорил об этом. Та же мысль выражена Гегелем: «Каждый народ имеет свое собственное государственное устройство; английское является государственным устройством англичан, и, если бы захотели дать его пруссакам, это было бы столь же абсурдно, как решение дать прусское государство туркам. Каждое государственное устройство есть только продукт развития духа народа и ступени развития сознания его духа. Это развитие необходимо требует поступательного движения, в котором ни одна ступень не может быть пропущена, нельзя опережать время, время всегда присутствует». Станет ли идея правового государства частью менталитета, духовной потребностью россиян, это покажет время. А вот идея «социального государства», достаточно быстро прижилась среди россиян. Потому что идея «социального государ- ства", первоначально сформулированная также не на российской почве, является не только идеей, концепцией, а неотъемлемым этапом развития любого государства, в том числе и России [7].

На наш взгляд, идея правового государства, именно в западном понимании, россиянами, можно сказать отвергается. И здесь важную роль как отмечают многие авторы, играет и особый исторический путь развития российского государства и общества, и менталитет, и духовная потребность россиян, прежде всего в справедливости, и морали. Говоря иными словами, правовое государство для россиян, прежде всего, должно ассоциироваться со справедливостью и духовностью.

Как пишет В. Г Баев, во все времена человечество искало ответ на вопрос: возможно ли существование справедливого государства? Пожалуй, только власть имущих не волновал данный вопрос. Независимость и личная свобода были основными ценностями западного правосознания [2]. Однако идеалом российского либерализма являлось равенство всех перед законом, а независимость и свобода для русского народа было лишь ступенью к другим более значимым целям, таким как равенство, социальная справедливость, коллективизм, поддержка государства. Именно эти цели преобладали в сознании нашего народа на протяжении веков.

Особое внимание необходимо уделить социальной справедливости, во-первых, потому что для российского народа социальная справедливость всегда занимала важное место, и это при том, что для россиян материальные ценности никогда не были в приоритете, а во-вторых, вопрос социальной справедливости, на наш взгляд, никогда не был таким актуальным как в новейшей истории России.

Известный юрист и философ Б. Н. Чичерин в своей работе "Собственность и государство»

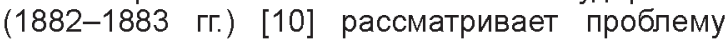
справедливого государства, в которой особое внимание обращает вопросам распределения национального богатства и социальной справедливости. Реализация данного принципа в правовом аспекте неизбежно ставит перед исследователем ряд вопросов: Как и по каким критериям должно осуществляться распределение национальных доходов? Имеет ли право государство вмешиваться в экономику страны ради общей пользы? Если да, то каковы пределы допустимого вмешательства?

Б. Н. Чичерин посвятил проблеме распределения богатства отдельную главу в работе «Собственность и государство», где, анализируя имеющийся опыт исследований по данной тематике, вывел собственную формулу. Определяя свою точку зрения на социальную справедливость, он использует неординарный подход, отнюдь не с социальных позиций. Автор полагает, что наиболее важными факторами обладания благами выступают не потребности, труд или способности и таланты личности, а вклад этой личности в экономическую деятельность, коэффициент ее полезности для экономики, выражая это следую- 
щим аргументом: «...справедливым мы должны признать такое распределение, которое дает каждому деятелю доход, сообразный с его значением в производстве». [10] По мнению правоведа, больше материальных благ должно достаться тому, кто внес больший вклад в их создание. Это благотворно скажется на росте производства, обеспечит экономике поступательное развитие и процветание и, в конечном счете, общий уровень жизни людей повыситься. Являясь противником материального равенства, считал что только завистливые люди требуют материального равенства, а справедливость на самом деле тут не причем: «...вместо установления одинаковой свободы для всех отбирать богатых в пользу бедных, как требуют социалисты, ... было бы не только нарушением справедливости, но вместе с тем извращением коренных законов человеческого общежития» [10]. Для равномерного распределения благ необходимо, чтобы система управления этим процессом была эфффективна. Следует повышать эффективность производства этих благ, и речь здесь идет не столько о производительности труда, результативности и экономической эффективности, сколько о социальной эффективности государства. Еще раз необходимо отметить, что государство становится эффективным в том случае, если у его граждан отсутствует нуждаемость в государственной помощи для удовлетворения минимальных потребностей.

Можно предложить разновидность модели социального государства - теоретическая модель эфффективного государства, в основе которой лежит представление о государстве как о политической организации общества. Цель данной организации - обеспечение единства и целостности общества, осуществляемое посредством государственного механизма управления делами общества, суверенной публичной власти, придающей праву общеобязательное значение, гарантирующей права и свободы гражданам, законность и правопорядок. Понимание эффективности рассматривается через призму социальной эфффективности. Данная модель является теоретической. При ее реализации необходимо учесть готовность органов управления как системы, субъектов ее управления и аппарата государства к ее пониманию, исполнению и реализации адекватно временным, историческим и эволюционным параметрам.

Критерии социальной эффективности призваны ориентировать государственное управление на потребности и проблемы общества и характеризовать управленческий уровень их разрешения, а социальный эффект, достигнутый при этом, должен не только сохраняться, но и усиливаться, учитывая на этапе реализации социальные последствия принятых управленческих решений.

К теме справедливого государства обращался и известный российский ученый М. А. Рейснер Понимание права через справедливость просматривается во всех его научных трудах. Он считал необходимым закрепление принципа справедли- вости в Конституции, для защиты хрупкого и подконтрольного власти права от злоупотреблений.

Однако многие современные ученные критично относятся к позиции М. А. Рейснера, основной целью теоретической конструкции которого, являлась ориентация на внедрение в правовую теорию классовой идеи.

В. Г. Баеву представляется ценной сама мысль М. А. Рейснера о неизбежности конституционного регулирования экономических отношений. Также очень важной идеей, по его мнению, является необходимость смещения акцента в системе показателей с измерения производства на измерение благосостояния [2]. Изменение курса государства в социально-экономической жизни страны неизбежно. В хозяйственной сфере меры, применяемые по регулированию экономики, неэффективны, так как действия государственных органов не носят системного характера. Объективно выражена необходимость во вмешательство в сферу экономики, и ее конституционной регламентации, так как если механизмы саморегуляции не дают результата, необходима жесткая управляющая рука государства для реанимации экономики страны. В то же время, в Основном законе, необходимо закрепить строго ограниченные рамки государственного вмешательства в частную сферу с целью перераспределения доходов. Проблема заключается в том, что очень сложно (если вообще возможно) разработать универсальные пределы направленного воздействия государств. Существует необходимость в создании гибкой системы государственных органов, которые будет интуитивно определять необходимость во вмешательство в экономику, исходя из реальных потребностей народа, и рамки вмешательства могут расширяться либо сужаться в конкретных политико-правовых условиях. Такова магистральная линия концепции конституционной экономики, нового научного направления, и ее реализация крайне сложная задача, однако очень важная, так как ответственность за осуществление принципа справедливости в ней возлагается на правящую элиту, которая должна отличаться высокой степенью нравственности и самоограничения, не допуская злоупотребления властью. Переориентацию государства в направлении защиты интересов малообеспеченных слоев следует начать с закрепления в Конституции категории «общей пользы», установления прогрессивного налогообложения формирования социальной ответственности бизнеса, прозрачности государственных органов.

К настоящему времени, историческое положение российского государства в системе развития страны, по мнению Д. Н. Миронова, с определенными оговорками можно сказать, восстановлено [5].

Модель эффективного государства рассматривается как социетальная система, в которой активно идет процесс смены отношений и процессов на уровне общества, и которая включает в себя функциональное взаимодействие основных структур - экономической, социальной, идеологической и политической. Каждая из структур соци- 
етальной системы эфффективного государства как модели социального государства, будучи ее элементом, но, выполняя свои функции и задачи при взаимодействии с другими элементами структуры, придает новое (системное) качество государству, не сводимое к качествам ее элементов. В результате этого возникает тенденция полной адаптации к формам и способам функционирования социетальной системы - эффективного государства, ее структурных и личностных элементов.

Дпя увязки с естественным ходом истории временный характер развития эффективного государства требует перестройки как структурных, так и личностных элементов социетальной системы - системы государственного управления и ее элементов (необходимо адаптировать ментальность и направление политики всех уровней государственного управления и ее составляющих к изменяющимся условиям жизни и состоянию общества), перехода от стратегии выживания к стратегии жизни.

В зависимости от места, которое та или иная структура начинает занимать в социетальной системе (эффективном государстве), а нас интересует система государственного управления, последняя начинает развиваться естественным путем, ощущая временные эволюционные потребности развития экономики и общества.

Основной результат функционирования эффективного государства как модели социального государства можно увидеть в отсутствии у граждан нуждаемости в государственной помощи для удовлетворения своих минимальных потребностей (естественных, физиологических, потребности в безопасности).

Теоретическая модель эфффективного государства, как было сказано выше, разработана с позиции социальной эффективности одного из элементов социального государства - механизма государства, государственного аппарата, ключевой характеристикой которого является качественный состав государственного управления, отвечающий заданным нами критериям и показателям.

Общество, государство и граждане заинтересованы в обоснованном воздействии права на социальные процессы. Эти процессы весьма разнообразны и предполагают «мягкие», «тонкие» и императивные методы правового регулирования. Конституционная характеристика социального государства предполагает выполнение всех социальных обязательств перед гражданами и обеспечение приоритета соответствующих бюджетных расходов. В правовой сфере генеральной перспективой становится формирование новой социальной концепции права, поскольку в последние годы право чаще всего ассоциируется с механизмом жесткого “одномерного» регулирования. Сугубо «текстовое» понимание затрудняет выявление его гуманистического потенциала и разнообразных способов влияния на сознание и поведение людей, поэтому пока не удается обеспечить личное влияние людей на процессы правотворчества и правоприменения и преодолеть такое отрицательное явление, как отчуждение от права.

В фокусе правового регулирования социальной сферы находятся социальные процессы и явления, происходящие в обществе. Речь идет о развитии межличностных, групповых профессиональных, национальных, миграционных, трудовых и иных отношений. Некоторые из них давно приобрели юридическую форму в виде соответствующих отраслей законодательства (например трудовое законодательство, законодательство o социальном обеспечении). Формируются отрасли научного, миграционного, спортивного законодательства. Правда, здесь немало проблем и противоречий. Еще более сложная ситуация с процессами в национальных, межнациональных территориальных и профессиональных отношениях. Здесь важен системный подход и согласование регулирования с помощью норм конституционного, административного, уголовного, муниципального и международного права, которые еще только предстоит разработать.

Социальная сорера традиционно регулировалась нормами административного права, где преобладает управленческий аспект, характерный для советского механизма государственного управления. Данный аспект сохраняется и в настоящее время, хотя введено много новых способов правового регулирования социальной сферы [9]. Развитие концепции социальных (публичных) услуг позволило акцентировать внимание на правовом механизме оказания услуг.

Обобщая тенденции правового развития в социальной сфере, можно отметить:

а) выделение соответствующих нормативно-правовых массивов из состава административного права и формирование самостоятельных отраслей законодательства;

б) комплексный характер регулирования в отраслях законодательства о здравоохранении, образовании, культуре, спорте и труде, а именно подвижное сочетание публично-правовых и частноправовых методов;

в) высокий удельный вес способов максимального регулирования и нормативного самоуправления:

г) большая степень децентрализации и самостоятельности медицинских, образовательных и иных учреждений в отношении вопросов управления;

д) потребность в активной деятельности граждан и их общественных объединений, в т.ч. профессиональных.

Несомненно, на качественный уровень правотворчества и эфффективность правового воздействия на результат в виде реализации социальной ориентированности государства негативное влияние оказывает поспешность правотворчества, его недостаточное научное осмысление, прогнозирование и планирование. Фокус внимания на достижение стратегических и тактических целей смещается в пользу решения ситуационных вопросов [8], недооцениваются важнейшие программные правовые акты, что приводит к хао- 
тичности в правотворчестве в целом и в социальной сфере в частности, к необходимости постоянных корректировок правовых актов посредством внесения изменений и дополнений

Таким образом, резюмируем, что оптимальное правовое регулирование социальной сферы не- полноценно и неэффективно вне использования новых методов проектирования нормативных актов и без использования механизмов стимулирования общественной деятельности.

\section{Литература}

1. Алебастрова И. А. Социальное государство: белые одежды голого короля или платье для Золушки? // Конституционное и муниципальное право, 2008. №20. С.2-11.

2. Баев В. Г. «Справедливое государство» как категория юриспруденции // Верховенство права и правовое государство: проблемы теории и практики: Материалы X международной научно-практической конференции. М.: РГУП, 2016. 289 C

3. Волгин Н. А. Социальное государство / Н. А. Волгин, Н. Н. Гриценко, Ф. И. Шарков / Учебник для вузов. М.: Социальные отношения, 2004. 45 с.

4. Глущенко П. П. Социально-правовая защита конституционных прав и свобод граждан (Теория и практика). /под общ. ред. В. П. Сальникова. СПб., Санкт-Петербургская академия, 1998. 448 с.

5. Миронов Д. Н. Основы формирования правового государства // Конституционное и муниципальное право. 2016. №3. C.6-10.

6. Моль Р. Наука полиции под началом юридического государства: Перевод с 3-го немецкого издания. Вып. 1 / Фон Моль Р.; Пер.: Р. Сементковский СПб.: Печ. В. И. Головина, 1871. [электронный ресурс] // http://www.bibliard.ru/ (дата обращения: 12.01.2019)

7. Родионова О. В. Правовое и социальное государство: проблемы соотношения // Верховенство права и правовое государство: проблемы теории и практики: Материалы X международной научно-практической конференции. М.: РГУП, 2016. С.28-40.

8. Смирнова М. Г. Социальные притязания: понятие и структура // Актуальные проблемы юридической науки: Сборник международной научной конференции конференции «Седьмые осенние юридические чтения» (м. Хмельницк, 28-29 ноября 2008 года): В 4-х т. 1 часть: Теория государства и права. Философия права. Международное право. Хмельницк: Хмельницкий университет управления и права, 2008. С. 110-116.

9. Социальное законодательство. Научно-практическое пособие (отв. ред.: д-р юрид. наук, проф. Ю.А. Тихомиров, канд. философ. наук, доцент В. Н. Зенков). М.: Контракт, Инфра-М, 2005. 352 с.

10. Чичерин Б. Н. Собственность и государство URL: http://www.klex.ru/ (дата обращения: 12.01.2019)

\section{References}

1. Alebastrova I. A. Social'noe gosudarstvo: belye odezhdy gologo korolya ili plat'e dlya Zolushki? (Social State: White Clothes of a Naked King or a Dress for Cinderella?) // Konstitucionnoe i municipal'noe parvo. 2008. No. 20. P. 2-11. (In Russian)

2. Baev V. G. "Spravedlivoe gosudarstvo» kak kategoriya yurisprudencii ("A Fair State" as a Jurisprudence Category) // Verhovenstvo prava i pravovoe gosudarstvo: problemy teorii i praktiki: Materialy $\mathrm{X}$ mezhdunarodnoj nauchno-prakticheskoj konferencii. Moscow: RSUP publ., 2016. P. 289. (In Russian)

3. Volgin N. A. Social'noe gosudarstvo (The Welfare State). Moscow: Social'nye otnosheniya, 2004. P.45. (In Russian)

4. Glushchenko P. P. Social'no-pravovaya zashchita konstitucionnyh prav i svobod grazhdan (Teoriya i praktika). (Social and Legal Protection of Constitutional Rights and Freedoms of Citizens (Theory and Practice) / ed by V.P. Sal'nikova. St.Petersburh: St.Petersburg Academy publ., 1998. 448 p. (In Russian)

5. Mironov D. N. Osnovy formirovaniya pravovogo gosudarstva (Basics of the Formation of the Rule of Law) /I Konstitucionnoe i municipal'noe parvo. 2016. №3. P.6-10. (In Russian)

6. Mol' R. Nauka policii pod nachalom yuridicheskogo gosudarstva (The Science of Police Under the Authority of a Legal State): Perevod s 3-go nemeckogo izdaniya. Issue. 1 / Fon Mol' R.; Per.: R. Sementkovskij St.Petesbrurg: V.I. Golovin's printing office, 1871 URL: http://www. bibliard.ru/ (Accessed: 12.01.2019). (In Russian)

7. Rodionova O. V. Pravovoe i social'noe gosudarstvo: problemy sootnosheniya (Legal and Social State: Problems of Correlation) // Verhovenstvo prava i pravovoe gosudarstvo: problemy teorii i praktiki: Materialy X mezhdunarodnoj nauchnoprakticheskoj konferencii. Moscow: RSUP publ., 2016. P.28-40. (In Russian)

8. Smirnova M. G. Social'nye prityazaniya: ponyatie i struktura (Social Claims: the Concept and Structure) // Aktual'nye problemy yuridicheskoj nauki: Sbornik mezhdunarodnoj nauchnoj konferencii konferencii «Sed'mye osennie yuridicheskie chteniya» (m. Hmel'nick, 28-29 noyabrya 2008 goda). Hmel'nick: Hmel'nick University of management and law, 2008. P.110116.

9. Social'noe zakonodatel'stvo (Social Legislation). M.: Kontrakt, Infra-M, 2005. 352 p. (In Russian)

10. CHicherin B. N. Sobstvennost' i gosudarstvo (Property and the State). Moskva, Izdatel'stvo Russkoj Hristiansko gumanitarnoj akademii, 2005. URL: http://www.klex.ru/ (Accessed: 12.01.2019). (In Russian)

\section{Сведения об авторах}

Галстян Инесса Шагеновна - кандидат юридических наук, доцент кафедры гражданско-правовых дисциплин филиала Московского института государственного управления и права в Карачаево-Черкесской республике (Черкесск) / inessagal@mail.ru 
Мелекаев Руслан Курманович - кандидат юридических наук, доцент кафедры теории и истории государства и права юридического института Северо-Кавказского федерального университета (Ставрополь) / merukus@yandex.ru

Information about the authors

Galstyan Inessa - PhD in Law, Associate Professor, Chair of Civil Discipline, Moscow Institute of Public Administration and Law (Branch in Karachay-Cherkess Republic) (Cherkessk) / inessagal@mail.ru

Melekaev Ruslan - PhD in Law, Associate Professor, Chair of Theory and History of State and Law NorthCaucasian Federal University (Stavropol) / merukus@yandex.ru 